\title{
ESTRATÉGIAS METODOLÓGICAS PARA O ENSINO DE PSICOLOGIA DA EDUCAÇÃO
}

\author{
Ágata Laisa Laremberg Alves Cavalcanti ${ }^{1}$ \\ Antonia Dalva França-Carvalho ${ }^{2}$ \\ Maria de Fátima Uchoa de Castro Macedo ${ }^{3}$
}

\section{CONSIDERAÇÕES INICIAIS}

Quando pensamos sobre a aula, enquanto espaço de aprendizagem, logo nos vem a mente aquela sala delimitada com quatro paredes e fileiras de carteiras, que acontece em determinado período. Essa visão faz parte do conceito escolar, que a aula possui, numa perspectiva tradicional. Segundo Masseto (2003), a aula é delimitada por um espaço físico e horário, em que professores e alunos interagem no processo de ensino e aprendizagem, em que a vivência se fundamenta no caráter de integração com a realidade. Assim, ao nos reportamos sobre a aula como vivência, reafirmamos que este espaço de aprendizagem, favorece e estimula a discussão, o estudo, à pesquisa, o dinamismo, ultrapassando o papel tradicional que a aula assume.

Para Farias et al (2014) a aula é considerada um espaço de diálogo no processo de aprendizagem, sendo um espaço-tempo em que professores e alunos desenvolvem ações interativas, transformando-as em um campo de debates dos mais variados temas, ultrapassando as paredes da sala de aula.

Nesse contexto, a experiência retratada ao longo deste artigo ${ }^{4}$ se refere as vivências realizadas ao longo da disciplina de Psicologia da Educação, tendo a

\footnotetext{
${ }^{1}$ Doutoranda em Educação. Programa de Pós-Graduação em Educação (PPGEd/UFPI). Professora Assistente do Curso de Licenciatura em Educação do Campo/Ciências da Natureza, do Campus Amílcar Ferreira Sobral, da Universidade Federal do Piauí. Pesquisadora do Núcleo Interdisciplinar de Pesquisas em Educação e Epistemologia da Prática Profissional (NIPEEPP). Email: agatalaysa@ufpi.edu.br

${ }^{2}$ Doutora em Educação. Professora do Programa em Pós-Graduação em Educação da UFPI e do Departamento de Fundamentos da Educação, do Centro de Ciências da Educação, da Universidade Federal do Piauí. Presidente da Comissão de Governança dos Programas de Formação Inicial de Professores, da Universidade Federal do Piauí. Líder do Núcleo Interdisciplinar de Pesquisas em Educação e Epistemologia da Prática Profissional (NIPEEPP). E-mail: adalvac@uol.com.br.

${ }^{3}$ Doutora em Educação Brasileira, Universidade Federal do Ceará. Professora Associado da Universidade Federal do Piauí. e-mail: fuchoamacedo@yahoo.com.br
} 
Professora Doutora Antonia Dalva França Carvalho, do Departamento de Fundamentos da Educação (DEFE/UFPI), como professora titular da disciplina.

Nesse sentido, delineamos como objetivo geral deste trabalho descrever as vivências do cotidiano em sala de aula, adquiridas durante o ensino de Psicologia da Educação para alunos do curso do Curso de Educação Física da UFPI. Além disso, buscamos conhecer os recursos didáticos utilizados ao longo da disciplina para o ensino de Psicologia da educação; descrever sobre a aula como espaço de aprendizagem e as relações estabelecidas entre o professor e alunos no processo de aprendizagem.

Para alcançarmos tais objetivos, recorremos a pesquisa participativa, descrita por Gil (2008), através de uma metodologia que parte do envolvimento dos pesquisadores e dos pesquisados no processo de pesquisa. O lócus de realização destas vivências foi a sala de aula do curso de Educação Física da UFPI, localizada no Bloco Anexo, do Centro de Ciências da Educação (CCE/UFPI). Os participantes envolvidos foram: a professora pesquisadora no desenvolvimento do estágio, a professora orientadora da disciplina e 41 alunos de graduação. A interação entre professor e alunos nos possibilitou vivenciar a realidade da sala de aula, percebendo o quanto uma aula pode ser exitosa para a aprendizagem dos alunos.

\section{A AULA: AMBIENTE DE APRENDIZAGEM}

Conforme iniciamos esta discussão, a aula assume um papel essencial no processo de aprendizagem, pois constitui um espaço de interações, diálogos e vivências que professores e alunos desenvolvem ao longo desse processo (RIOS, 2002).

A aula é, pois, um lugar privilegiado para o processo de aprendizagem, ao produzir um espaço de encontros e trocas de saberes, não se limitando a fala exclusiva do docente. Por isso, Farias et al (2014) afirmam que esta concepção de aula assume um caráter transformador, tendo a mediação como tarefa docente, através do compromisso, confiança, colaboração e respeito mútuo entre os sujeitos envolvidos.

\footnotetext{
${ }^{4}$ Este artigo possui sua versão original publicada na obra FRANÇA-CARVALHO, A. D. et al. (org.) Notas de aula: dialogando sobre práticas de aprendizagens na escola e na universidade. Teresina, EDUFPI, 2017.
} 
Assim, faz-se necessário superar a perspectiva tradicional em que a aula é concebida, visando promover nos alunos uma atitude crítica frente à realidade. É preciso "trazer para as situações e aula o contexto sociohistórico, em outras palavras, a prática social dos sujeitos implicados no ato educativo" (FARIAS et al, 2014, p.169). Ou seja, o professor necessita entender que o conhecimento é fruto de interações entre os sujeitos com o objeto de estudo.

Por isso, é preciso que professores e alunos se relacionem, através do diálogo, interagindo e produzindo saberes para sua formação, no espaço privilegiado em que a aula acontece. Quando professor e aluno fazem a aula juntos, ambos ensinam e aprendem, constroem e reconstroem experiências (RIOS, 2008). Daí a necessidade do professor utilizar estratégias de ensino baseadas na construção de relações mais democráticas entre os atores.

E é nessa perspectiva que as aulas foram desenvolvidas ao longo da disciplina de Psicologia da Educação, priorizando a interação entre professor e alunos, na construção do conhecimento e do respeito. As aulas constituíram um espaço de aprendizagem para ambos os envolvidos nesse processo, tendo a prática pedagógica docente apoiada no pensamento dialético de formulação do conhecimento.

Segundo Pimenta e Anastasiou (2005), os futuros professores do Ensino Superior irão desenvolver novas maneiras de ensinar conforme a necessidade e à medida que vão vivenciando novas maneiras de aprender. Por isso, a importância do estágio de docência, como momento de oportunizar a construção do saber fazer docente.

As autoras afirmam ainda, que é preciso considerar nos processos de formação de professores, os saberes do conhecimento (ninguém ensina o que não sabe), os saberes pedagógicos (saber ensinar), os saberes da experiência do professor (acumulados ao longo da vida). Esses saberes são essenciais para o saber fazer docente, que alicerçam a prática do futuro professor, possibilitando transformar o ensino.

Dito isso, apresentamos a seguir, o percurso metodológico da disciplina Psicologia da Educação, delineando sobre as vivências adquiridas em sala de aula, através das aulas ministradas da turma de Educação Física. 
A experiência de docência ocorreu no período de outubro de 2015 a fevereiro de 2016, na disciplina de Psicologia da Educação, para o curso de Educação Física. A turma era composta por 41 alunos, tendo alguns alunos do $4^{\circ}$ e $5^{\circ}$ período, mas a maioria é composta pelos alunos do $2^{\circ}$ período. A experiência oportunizada pela realização do estágio de docência é de grande importância para a o desenvolvimento profissional docente, pois reafirma a escolha pela profissão.

As aulas iniciaram dia 20 de outubro de 2015 , no qual tivemos o primeiro contato com a turma, realizando uma breve apresentação de cada um e também das professoras. Em seguida, criamos em conjunto, um contrato pedagógico, no qual se estabelecia algumas condutas de convivência, para que o dia-a-dia na sala de aula fosse harmônico e produtivo. Esse contrato constituído entre professor e alunos, segundo Aquino (2000, p.60) visa "o estabelecimento de condutas para ambas as partes, até, e principalmente, a explicitação contínua dos objetivos, limites e horizontes da relação".

Assim, no contrato pedagógico firmado entre a turma e as professoras, incluíam algumas condutas, tais como: manter celular no silencioso ou desligado no momento da aula, ter responsabilidade com as atividades, não chegar atrasado à aula, dentre outras criadas pelos próprios alunos.

As diversas atividades foram planejadas para que esta disciplina contribuísse para a formação dos futuros professores de Educação Física, no campo da Psicologia da Educação. A Tabela 1, a seguir, mostra a síntese das atividades realizadas ao longo da disciplina, relacionando-as com alguns recursos didáticos e conteúdos abordados.

Tabela 1 - Síntese dos recursos didáticos e conteúdos utilizados na disciplina de Psicologia da Educação.

\begin{tabular}{c|c|c}
\hline $\begin{array}{c}\text { ATIVIDADE/RECURSOS } \\
\text { DIDÁTICOS }\end{array}$ & DESCRIÇÃo & \multirow{2}{*}{ CONTEÚDO ABORDADO } \\
\cline { 1 - 2 } Música & $\begin{array}{c}\text { Metamorfose Ambulante - Raul } \\
\text { Seixas }\end{array}$ & \multirow{2}{*}{ Identidade } \\
\hline Poema & $\begin{array}{c}\text { Morte e Vida Severina - João } \\
\text { Cabral de Mello Neto }\end{array}$ & $\begin{array}{c}\text { Construção social do sujeito } \\
\text { O enigma de Kaspar Hauser } \\
\text { Introdução à Psicanálise }\end{array}$ \\
\hline Filmes & Freud: Além da Alma & Evolução da Psicologia \\
\hline Fichas temáticas & $\begin{array}{c}\text { Construção da linha do tempo da } \\
\text { Psicologia }\end{array}$ & A Psicologia e Educação \\
\hline Roteiro de Estudo & Questionário sobre o conteúdo & . \\
\hline
\end{tabular}




\begin{tabular}{|c|c|c|}
\hline Grupos de Trabalhos & $\begin{array}{l}\text { Apresentação de grupos com } \\
\text { temas sobre aprendizagem } \\
\text { Quiz de perguntas e respostas }\end{array}$ & $\begin{array}{c}\text { Aprendizagem: atitudes, normas e } \\
\text { valores }\end{array}$ \\
\hline Apresentação em slides & Aula expositiva & $\begin{array}{c}\text { Aprendizagem } \\
\text { Contribuições da psicanálise à } \\
\text { Educação - Teoria Psicossexual } \\
\text { de Freud }\end{array}$ \\
\hline Seminários & Apresentação didática em grupos & $\begin{array}{l}\text { Teorias da Aprendizagem: } \\
\text { Inatista-maturacionista } \\
\text { Behaviorismo - Skinner } \\
\text { Psicogenética de Piget } \\
\text { Histórico-cultural de Vygotsky } \\
\text { Aprendizagem Significativa - } \\
\text { Ausubel } \\
\text { Psicogenética de Wallon }\end{array}$ \\
\hline Painéis & $\begin{array}{c}\text { Confecção de painéis sobre a } \\
\text { temática das teorias da } \\
\text { aprendizagem abordadas nos } \\
\text { seminários } \\
\end{array}$ & Teorias da Aprendizagem \\
\hline Portfólio & $\begin{array}{c}\text { Construção do portfólio da } \\
\text { disciplina }\end{array}$ & Todo conteúdo da disciplina \\
\hline
\end{tabular}

Fonte: Autoras, 2016.

Na figura abaixo, apresentamos a formação da Linha do Tempo da Psicologia desenvolvida a partir da leitura do texto sobre a Evolução da Psicologia. Essa atividade foi realizada pelos alunos, que transcreveram no quadro branco as principais características de cada período histórico. Essa atividade envolveu trabalho em grupo, com apresentação das equipes.

Figura 1 - Construção da linha evolutiva da psicologia no quadro branco.

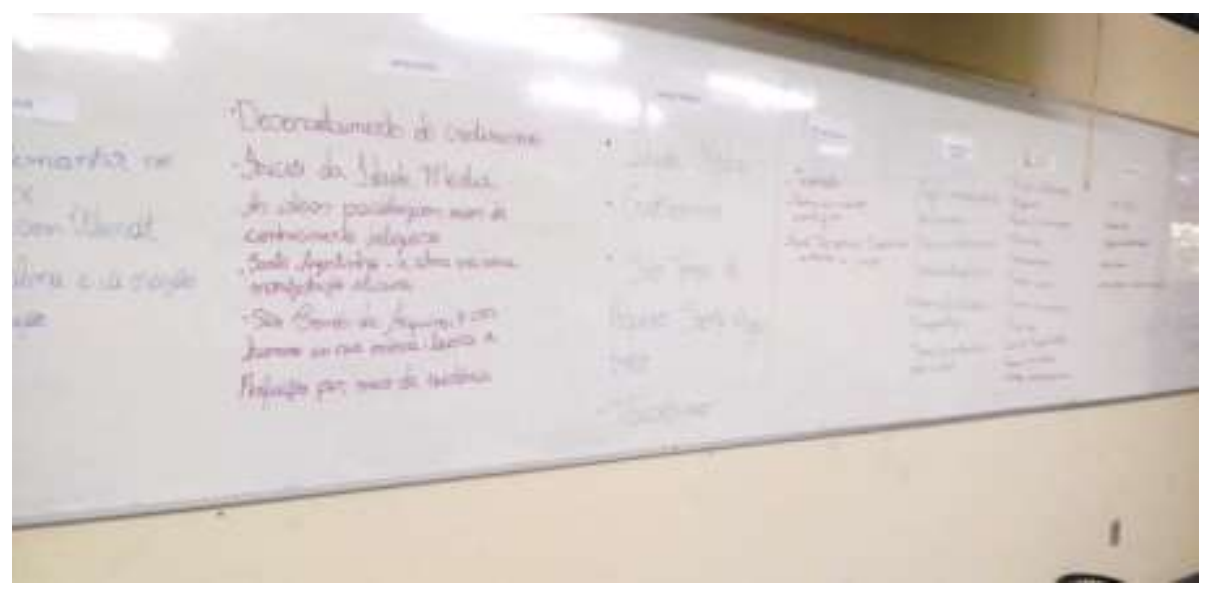

Fonte: Autoras, 2016.

Para trabalharmos a temática da identidade com os alunos, utilizamos além dos textos propostos, a música de Raul Seixas, Metamorfose Ambulante e um 
poema de João Cabral de Melo Neto, Morte e Vida Severina. A proposta foi articular os conteúdos vistos na teoria, com a prática proporcionada pela interação dos alunos com a música e o poema. Desde modo, a turma foi dividida em dois grupos, onde, um ficou com a música, desenvolvendo uma coreografia e o outro com o poema, trabalhando-o por meio da dramatização. Na figura 2 e 3, apresentamos as atividades desenvolvidas pelos dois grupos.

Figura 2 - Dramatização do Poema "Morte e Vida Severina". Fonte: Autoras, 2016.

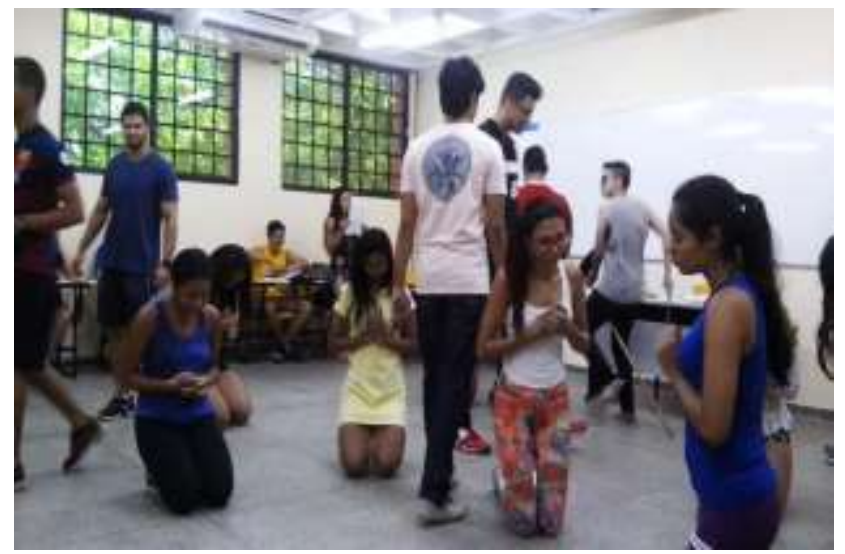

Fonte: Autoras, 2016.
Figura 3 - Alunos desenvolvendo uma coreografia da música "Metamorfose Ambulante". Fonte: Autoras, 2016.

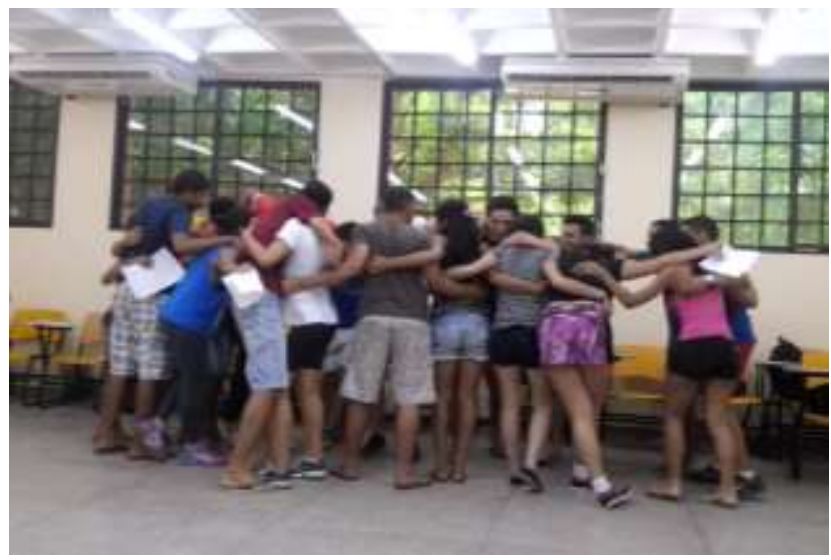

Fonte: Autoras, 2016.

Segundo Souza et al (2010), "a mediação que a música proporciona é um momento ideal para a promoção da aprendizagem devido a gama de informações que ela nos oportuniza trabalhar". Assim, o conteúdo de identidade foi trabalhado a partir da contextualização com os trechos da música, dinamizando o processo de aprendizagem dos alunos.

Essa atividade envolveu a participação de toda a turma, alunos e professores, pois nesse momento houve uma grande interação proveniente do dinamismo dessa atividade. Nesse contexto, sob a perspectiva de Lopes (1991), entendemos que o professor deve ser criativo, buscando novas estratégias de ensino.

O professor criativo, de espírito transformador, está sempre buscando novas práticas e um dos caminhos para tal fim seria dinamizar as atividades desenvolvidas em sala de aula. Uma alternativa para a dinamização seria a variação das técnicas de ensino utilizadas, outra seria a introdução de inovações das técnicas amplamente conhecidas e empregadas. (LOPES, 1991, p.35) 
Logo, aliado a busca de novas estratégias de ensino, se faz necessário compreender o universo em que o aluno esta inserido, levando em consideração seus conhecimentos e conceitos já adquiridos, para que novos saberes sejam inseridos somados nesse processo de aprendizagem.

Outra proposta de atividade foi à confecção de painéis acerca das Teorias da Aprendizagem, apresentadas através de seminários. $O$ objetivo desta atividade foi possibilitar aos alunos a capacidade de identificar as principais características de cada teoria e apresentar em forma de painel, sintetizando a importância de cada uma para a formação de professores. A figura abaixo destaca alguns painéis confeccionados pelos alunos e dispostos no quadro, após a apresentação.

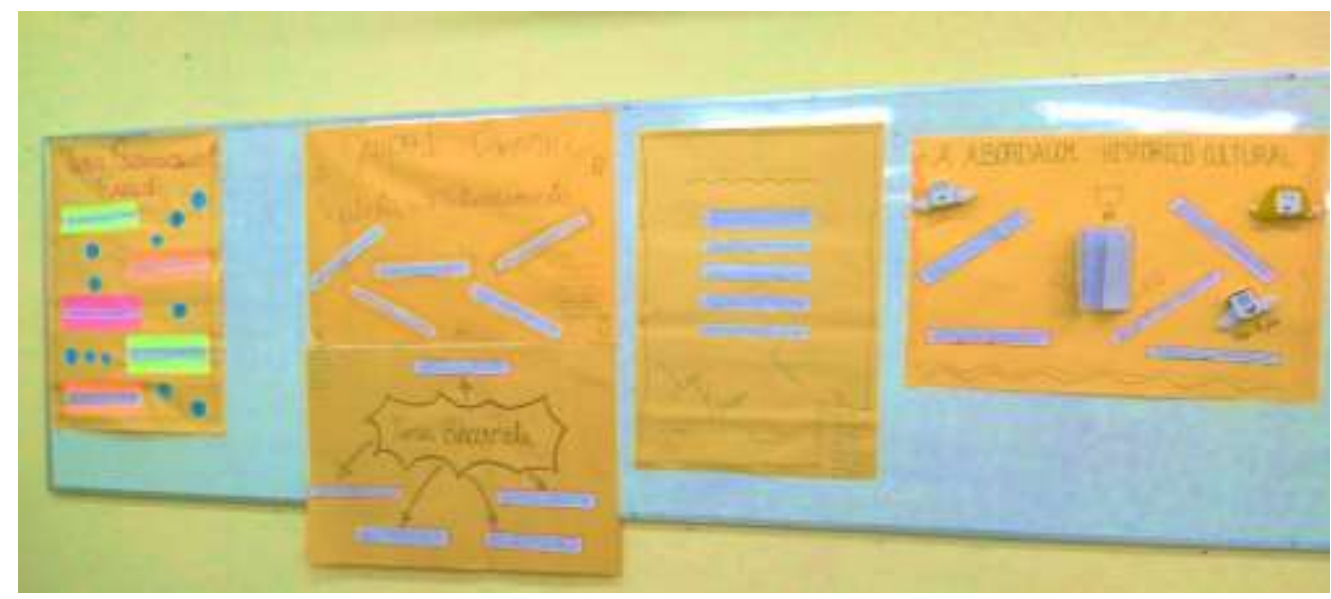

Figura 4 - Apresentação dos painéis. Fonte: Autoras, 2016.

Candau (1999) assinala que educar é colaborar para que professores e alunos - nas escolas e organizações - transformem suas vidas em processos permanentes de aprendizagem.

A última proposta de atividade da disciplina foi através da utilização do Portfólio como instrumento de avaliação, devido a importância que este apresenta na construção das aprendizagens dos alunos, uma vez que esta ferramenta permite registrar vivências, atividades desenvolvidas ao longo de um período. Nessa perspectiva, a utilização do portfólio é:

[...] para o professor e para o aluno, um retrato dos passos percorridos na construção das aprendizagens. Essa característica de registro diário tem o sentido de mostrar a importância de cada aula, de cada momento, como uma situação de aprendizagem. O aluno é, então, avaliado por todos esses momentos. (PERNIGOTTI et al., 2000, p.55) 
Por isso, o portfólio foi utilizado como a última avaliação da disciplina, para que os alunos registrassem cada momento de aprendizagem vivenciado nas diversas atividades desenvolvidas ao longo da disciplina de Psicologia da Educação. Hernández (1998, p.100) afirma que a confecção do portfólio proporciona ao aluno "evidências do conhecimento que foi construído, das estratégias utilizadas e da disposição de quem o elabora em continuar aprendendo".

E nessa perspectiva, os alunos, entregaram os portfólios, abordando com muita criatividade as, atividades desenvolvidas, os registros de trabalhos, seminários, inserindo suas reflexões sobre o que aprenderam na disciplina, como mostram as Figuras 5 e 6.

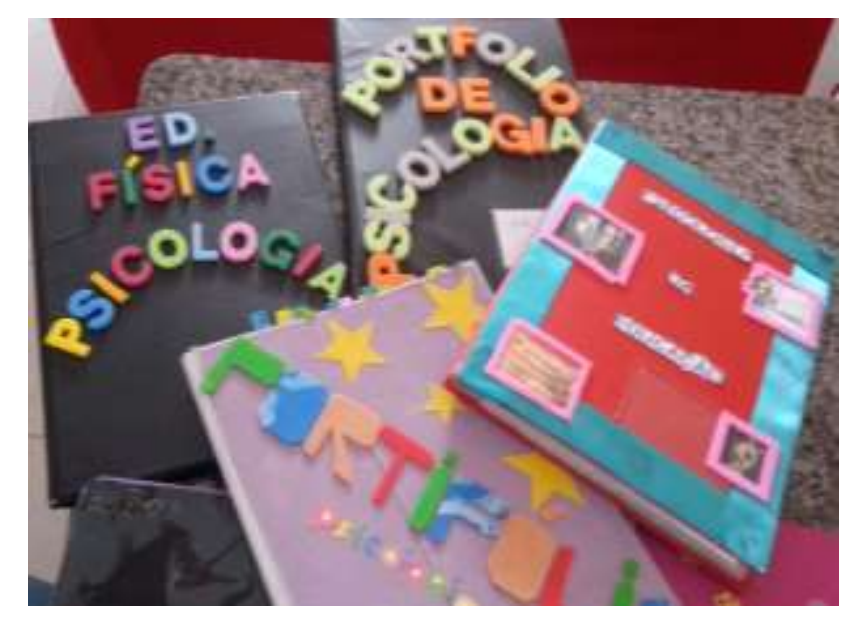

Figura 5 - Alguns portfólios confeccionados pelos alunos. Fonte: Autoras, 2016.

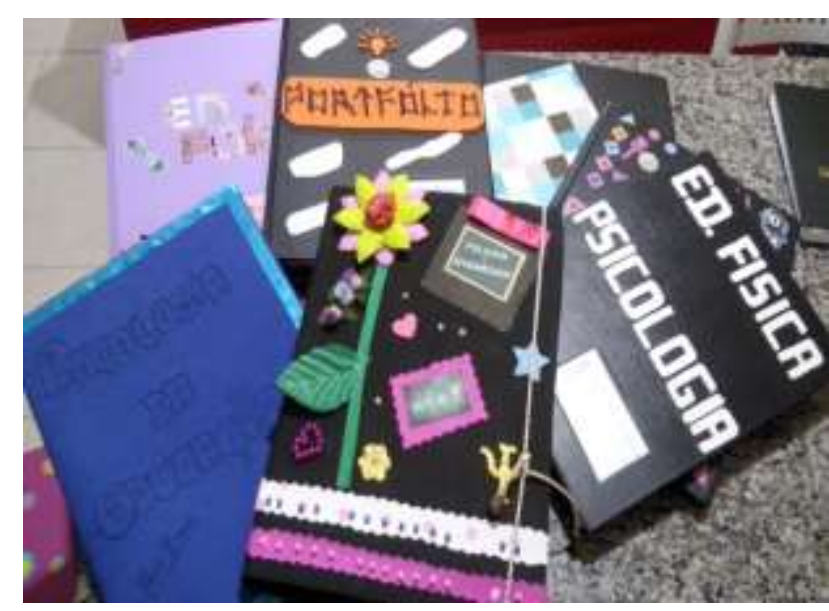

Figura 6 - Portfólios confeccionados pelos alunos da turma. Fonte: Autoras, 2016.

Nesse sentido, concordamos com Vilas Boas (2001), ao utilizar o portfólio como um importante instrumento de avaliação, que reúne as produções dos alunos e professores desenvolvidas em determinado tempo, para que, eles próprios reconheçam seus esforços, seus progressos e suas necessidades nas diversas áreas do conhecimento.

Portanto, é no cotidiano da sala de aula, dos momentos de planejamento e orientações que desenvolvermos essa importante etapa da formação docente e tomamos como base as exposições de Candau (1997, p.81-82), ao considerar, que através do estudo sobre o cotidiano docente, "é possível aprender o movimento de busca criativa presente na dinâmica escolar. E este movimento gerado no interior de 
experiências particulares transcende sua própria singularidade e aponta em direção ao 'genérico'".

É "no cotidiano da ação docente, que encontramos evidências do saber e do fazer pedagógicos do professor que pode manifestar como uma práxis em seus diversos níveis" (PIMENTA, 2002, p.49). Assim, o cotidiano exerce um grande papel na práxis do professor, principalmente ao considerarmos a sala de aula um espaço em que se desenvolve toda a ação docente.

As experiências adquiridas ao longo da realização do estágio de docência, no âmbito do curso de mestrado em educação, proporcionou esse sentimento de busca criativa por novas maneiras de ensinar, de envolver os alunos. Para Schimitz (1993) cabe ao professor, ser dinamizador do processo de aprendizagem, estar atento às diferentes situações para que os recursos cumpram sua finalidade, que é, principalmente, facilitar a aprendizagem integrada e dinâmica.

\section{VIVENCIANDO O COTIDIANO DA SALA DE AULA}

Ao longo das vivências realizadas no cotidiano da sala de aula, entendemos que os saberes pedagógicos são aqueles constituem o saber-fazer, aqueles mobilizados e elaborados no percurso da ação docente (PERRENOUD, 2001). Ou seja, é aquele que se constrói no cotidiano do trabalho docente, que possibilita a interação com os alunos, no contexto em que atua, fundamentando sua ação (AZZI, 2002). Por isso, esses saberes construídos se expressam no cotidiano da prática docente. Nesse contexto, enquanto docente pensamos o processo de ensino, refletindo sobre suas possibilidades, limitações pessoais e profissionais.

Assim, a construção dos saberes pedagógicos oportunizados pelo Estágio de Docência, contribuiu para o desenvolvimento da prática profissional docente. Além disso, identificamos o universo de saberes que permeiam a prática do professor ao conduzir uma disciplina para o curso de formação de professores. O professor estagiário do Ensino Superior, em constante processo de formação, participa da formação de futuros professores, neste caso, licenciandos do Curso de Educação Física, permitindo a troca de saberes, experiências, na construção do conhecimento por ambos os sujeitos desse processo de ensino e aprendizagem.

Deste modo, a identidade profissional docente vai se construindo ao longo das vivências da docência, através do significado que o professor atribui, enquanto 
ator e autor, à atividade docente realizada no seu cotidiano, com base em seus valores, no seu modo de viver, na sua história de vida, em seus saberes, angústias, anseios, buscando o sentido de ser professor em sua vida (PIMENTA; ANASTASIOU, 2005).

Com relação as aulas, percebemos que esta constitui um espaço de aprendizagem, pois proporciona o surgimento de aprendizes, ao tempo que se torna um encontro apaixonante e, desafiador e realizador, tanto para o professor quanto para os alunos, sempre pautada nas interações que há entre os atores envolvidos. A elaboração e execução das aulas também contribuíram para nossa prática profissional docente do Ensino Superior, numa perspectiva transformadora, humana e dialógica.

No contexto da ação docente, segundo Sacristán (1999) a intencionalidade constitui uma das condições necessárias para a ação e, cabe ao educador compreender esse elemento fundamental no contexto ao qual está inserido. Afinal, a educação não é algo espontâneo, pois envolve uma aprendizagem construída, através da seleção de possibilidades, de conteúdos, de caminhos.

Eis que a aula é o resultado dessa construção, possibilitada pelo planejamento, que tem como foco a aprendizagem do aluno e também do professor. É nessa perspectiva que preparamos cada aula ministrada ao longo da disciplina, pensando nessa parceria entre professor e aluno, para tornar as aulas mais interativas e exitosas.

Desse modo, ao longo do Estágio de Docência, muitos saberes foram construídos. A prática desenvolvida permitiu reafirmar a escolha pela profissão professor, ao tempo que construímos a nossa identidade profissional. Ser professor é uma profissão que requer inovação das estratégias de ensino, criatividade e, sobretudo, amor pelo que se faz.

Por isso, as vivências oportunizadas ao longo do cotidiano em sala de aula contribuíram significativamente para o desenvolvimento profissional, enquanto futura educadora do Ensino Superior.

\section{REFERÊNCIAS}

AQUINO. Júlio Groppa (Org.). Do cotidiano escolar: ensaios sobre a ética e seus avessos. São Paulo: Summus, 2000. 
AZZI, S. Trabalho pedagógico: autonomia didática e construção do saber pedagógico. In: PIMENTA, S. G. Saberes da docência e atividade docente. São Paulo: Cortez, 2002. p.35-60.

BRASIL. Portaria № 76, de 14 de abril de 2010. Coordenação de Aperfeiçoamento de Pessoal de Nível Superior - CAPES. Estabelece o novo Regulamento do Programa de Demanda Social constante do Anexo a esta Portaria. 2010. Diário Oficial da União, Seção 1, 19 abr, 2010. Disponível em: $<$ https://www.capes.gov.br/images/stories/download/legislacao/ Portaria_076_RegulamentoDS.pdf>. Acesso em: 03 ago. 2016.

CANDAU, V. M. Rumo a uma nova didática. 10. ed. Rio de Janeiro: Vozes, 1999. Magistério: construção cotidiana. Petrópolis, RJ: Vozes, 1997.

CAVALCANTI, A. L. L. A..; FRANÇA-CARVALHO, A. D. A aula como espaço de aprendizagem: o ensino de Psicologia da Educação na formação de professores. In: FRANÇA-CARVALHO, A. D. et al. (org.). Notas de aula: dialogando sobre práticas de aprendizagens na escola e na universidade. Teresina, EDUFPI, 2017. p. 60-75.

FARIAS, I. M. S de; SALES, J. de O. C.B.; BRAGA, M. M. S. de C.; FRANÇA, M do S. L. M. Didática e Docência: aprendendo a profissão. 4. ed. Brasília: Liber Livro, 2014. (Coleção Formar).

GIL, A. C. Métodos e técnicas de pesquisa social. 6. ed. São Paulo : Atlas, 2008.

HERNÁNDEZ, F. Transgressão e mudança na educação: Os projetos de trabalho. Porto Alegre: Artmed, 1998.

LOPES, Antônia Osima et al. Técnicas de ensino: aula expositiva: superando o tradicional. Campinas: Papirus, 1991.

MASSETTO, M. T. Aula: ambiente de aprendizagem e de trabalho profissional do docente. In: Competência pedagógica do professor universitário. São Paulo: Summus, 2003. p.73-83.

PERNIGOTTI, J. M.; SAENGER, L.; GOULART, L. B.; ÁVILA, V. M. Z. O portfólio pode muito mais do que uma prova. Pátio, Porto Alegre, n.12, ano 3, p. 54-56, fev./abr. 2000.

PERRENOUD, P. A. Ensinar: agir na urgência, agir na incerteza. 2. ed. Tradução Claudia Schilling. Porto Alegre: Artmed, 2001.

PIMENTA, S.G.; ANASTASIOU, L. das G. C. Docência no ensino superior. 2. ed. São Paulo: Cortez, 2005. (Coleção Docência em Formação).

PIMENTA, S. G. Formação de professores: identidade e saberes da docência. In: p.15-34. Saberes da docência e atividade docente. São Paulo: Cortez, 2002. 
. O estágio na formação de professores: unidade teoria e prática? São

Paulo: Cortez, 1994.

RIOS, T. A. A dimensão ética da aula ou o que nós fazemos com eles. In: VEIGA, I. P. A. (Org.). Aula: gênese, dimensões, princípios e práticas. Campinas: Papirus, 2008.

Compreender e ensinar: por uma docência da melhor qualidade. 3. ed. São Paulo: Cortez, 2002.

SACRISTÁN, J. GIMENO. O que move a ação educativa? A racionalidade possível na pós-modernidade e a relação teoria-prática. In: educação. Porto Alegre: Artes Médicas Sul, 1999. Poderes instáveis em

SCHMITZ, E. Fundamentos da Didática. 7. ed. São Leopoldo: UNISINOS, 1993.

SOUZA, Elíria; FONSECA, Francisca; SILVA, Valdison; NETO, José. A música no contexto acadêmico: um instrumento didático. $V$ Congresso Norte-Nordeste de Pesquisa e Inovação - CONNEPI. Anais... Maceió, 2010. Disponível em: http://connepi.ifal.edu.br/ocs/index.php/ connepi/CONNEPI2010/paper/viewFile/1604/849>. Acesso em: 01 ago. 2016.

VERHINE, R.E.; DANTAS, L.M.V. Estágio de Docência: conciliando o desenvolvimento da tese com a prática em sala de aula. Revista Brasileira de PósGraduação. Dez. 2007, v.4, n.8, p 171-191.

VILAS BOAS, B. M. F. O projeto Político-Pedagógico e a Avaliação. In: VEIGA, I.; RESENDE, L. (org.). Escola: Espaço do Projeto Político-Pedagógico. Campinas: Papirus, 2001. 